\title{
Konkrete uitdagings vir die kerk vandag ${ }^{1}$
}

J J Kritzinger

(Universiteit van Pretoria)

\section{ABSTRACT}

\section{Concrete challenges for the South African church today}

In a recent publication No Quick Fixes a number of knowledgeable people dealt with some contemporary challenges to the church in its mission in the South African context. In this article the reader is introduced to these, but the focus is on those aspects of the challenge which arise from the two main influences in the spiritual sphere: on the one hand the overwhelming secularising influence of the modern western worldview, and on the other hand the increasing emphasis on the return to the values of traditional Africa, as formulated in the movement for the African Renaissance.

\section{INLEIDING}

Twee geestestrominge beïnvloed die resepsie en die vormgewing van die evangelie in Suid-Afrika ten diepste: die ewig teenwoordige, maar deesdae opnuut beklemtoonde kulturele en godsdienstige agtergrond van Afrika; en die moderne gesekulariseerde denk- en leefwyse tipies van die verwesterse mens. Waar die een die mens bind aan ' $\mathrm{n}$ diep religieuse, magiese bestaan, word die ander leefwyse gekenmerk deur optrede asof God en die religieuse nie bestaan nie. Die eerste is kommunaal, en beteken ' $n$ entoesiastiese godsdienstige organisasie, die ander veroorsaak ' $n$ onttrekking van godsdienstige organisasie, ' $n$ negatiewe, defensiewe kerklike lewe, met min entoesiasme en spekulatiewe denke.

As ons sending definieer as die betrokkenheid van die kerk in die wêreld, is dit duidelik dat die uitdagings vir die kerk in Suid-Afrika grootliks deur hierdie konteks bepaal sal word. Ek dink nie dat die taak van die kerk in die wêreld beperk moet word tot die kommunikasie van die evangelie aan hulle wat nog nie gehoor het nie, of wat nog nie positief gereageer het op die uitnodiging van die evangelie nie. Natuurlik is dit een van die kern dimensies van die kerk se taak ${ }^{2}$, maar in die Suid-

\footnotetext{
Referaat gelewer by EVTO en die SSK van die Vrystaat se konferensie oor "Kerkwees in die hedendaagse Suid-Afrika", Bloemfontein, 17 Maart 2003.

2 Ekself werk graag met die sg. driedimensionele verstaan van sending, soos uitgewerk in my werkie Die Onvoltooide Sendingtaak in Suid-Afrika (1988:34-36). Die eerste dimensie is evangelisering (kerygma), maar daarby kom die aksies van diakonia (diensbetoon) en koinonia (gemeenskapstigting). In hierdie definisie het ek veral gebou op David Bosch se geskrifte.
} 
Afrikaanse konteks sou dit die taak oneindig verskraal ${ }^{3}$. Dit is hierdie beperkte siening wat veroorsaak dat die kerk in Suid-Afrika meen dat sending alleen maar in ander wêrelddele te doen is ${ }^{4}$.

\section{SUID-AFRIKAANSE UITDAGINGS OP VELE TERREINE}

In Suid-Afrika is daar verskeie voor-die-hand-liggende uitdagings vir die kerk. In ons onlangse werk No Quick Fixes. The Challenge of Mission in a Changing South Africa (2002) het ons aan 'n hele paar hiervan aandag gegee. In hierdie artikel gaan ek die meeste daarvan nie behandel nie, maar eintlik aandag gee aan daardie wat direk met die tema van die dag verband hou. Ter inleiding kan ons egter enkele opmerkings maak oor sommige van die ander uitdagings.

Die politiek is altyd ' $\mathrm{n}$ terrein waar die kerk grondige, al is dit sensitiewe, kritiese bydraes moet lewer ${ }^{5}$. Die feit dat ons Gereformeerde kerke in Suid-Afrika 'n ongelukkige rekord opgebou het van onkritiese betrokkenheid by die politiek, moet nie veroorsaak dat ons nie weer bereid sal wees om vorentoe ons profetiese stem te laat hoor nie. Vandag is dit waarskynlik die nuwe ideologie en kultuur van menseregte wat krities-solidêre aandag verdien. Sonder om negatief oor te kom, is dit nodig dat hieroor krities nagedink moet word. Dalk is dit nie soseer die klem op die regte van (alle) mense wat gekritiseer moet word nie, maar die ideologiese trekke wat soms die toepassing kenmerk. Hier dink ek aan die klem - dikwels ongebalanseerd - wat gelê word op die regte van misdadigers, ongehude ouers, homoseksuele, ensovoorts, soveel so dat dit soms voorkom asof die regte van die gewone mense aangetas word.

' $n$ Ander terrein wat vir die kerk besonder belangrik is, is dié van die godsdienstige regte. Godsdiensvryheid is belangrik, en moet verseker word. Natuurlik moet die kerk in sy sending steeds eervol optree teenoor mense van ander godsdienstige oortuigings. Dit staan vas. Maar is dit reg dat mense skynbaar die reg ontneem word om hulle geloofsoortuigings

\footnotetext{
3 Dit sou nie heeltemal onwaar wees as gesê word dat Suid-Afrika "ge-evangeliseer" is nie. Nie alleen is feitlik drie-kwart van die bevolking volgens die sensusopname "christene" nie, maar selfs die nie-christene kan nie beweer dat hulle nog nie met die evangelie kennis gemaak het nie.

4 Die bedoeling van hierdie opstel is juis om aan te toon watter besondere sendinguitdagings daar wag vir die kerk in Suid-Afrika.

5 Die politiek het - soos die etimologie aandui - te doen met die ordening van die leefwêreld (die stad). As die soeklig van die Woord nie val op hierdie terrein nie, is die kerk klaarblyklik ontrou aan sy roeping.
} 
met ander te deel? Is dit reg dat in die skole spesifieke godsdienstige oortuigings teengewerk word met ' $\mathrm{n}$ algemene religieusiteit?'

Nog ' $n$ terrein is die sosio-ekonomiese. Dat meer as helfte van die Suid-Afrikaanse bevolking onder die broodlyn leef, is skokkend (Beukes 2002:105). Dat ons land in terme van die verhouding tussen ryk en arm een van die mees wangebalanseerde gemeenskappe ter wêreld is, is totaal onaanvaarbaar (Beukes 2002:105). Armoede het soveel gesigte (Kritzinger 1988:101-104), maar elk daarvan konfronteer die kerk met 'n onontwykbare opdrag: "gee julle vir hulle iets om te eet!" (Lk 9:13).

In No Quick Fixes wys ons op die twee vlakke van aandag wat hieraan gegee moet word. Eerstens is daar die strukturele vlak: daar is ongeregtigheid aan die werk in die lands- en wêreldekonomie. Is die kerk bedag op hierdie uitdagings? Berus ons maar in TINA ("there is no alternative"), of roep ons uit: THEMBA ("there must be an alternative", themba spel ook "hoop" in Zoeloe) ${ }^{7}$. Maar dan is daar ook die praktiese stryd teen armoede in al sy gestaltes, op die grond. Ons kies vir " $n$ benadering wat gesinne, huisgesinne ten goede kom. Nie alleen is dít die plek waar die armoede aan die lyf gevoel word nie, maar dit is ook die plek waar die stryd aangeknoop en oorwin moet word ${ }^{8}$. Dit is ook (tussen hakkies) die plek waar die kerk aan/afwesig is!

Op maatskaplike terrein wil ek maar net op twee sake wys: die krisis in die gesondheidsdienste, en in besonder op die MIV/vigspandemie wat op almal se lippe is. Hierdie is " $n$ krisis wat almal toenemend raak, direk, maar ook indirek met die dreigende ineenstorting van die dienste en selfs die ekonomie van die land. Wat 'n uitdaging op versorgingsvlak, om nie te praat van voorkoming nie ${ }^{9}$.

Die ander saak op almal se lippe is natuurlik die onaanvaarbare vlak van misdaad. Almal is bewus daarvan, dit raak ons op elke lewensterrein. Maar doen die kerk iets positiefs aan die saak, behalwe om kollektief ' $n$ keel daaroor op te sit? Ja, ons preek teen misdaad, maar het die kerke nog enige invloed op hulle mense? ${ }^{10}$ Of is dit net die persentasie "nie-christene" wat vir al die misdaad verantwoordelik is?

6 Oor hierdie terrein kan die volgende hoofstukke nagelees word in No Quick Fixes: hoofstuk 3 van prof Gerrie Lubbe (2002:61-69), hoofstuk 5 deur dr Noko Frans Kekana (2002:81-89), en hoofstuk 11 van dr Vic Brink (2002:147-161).

7 Beukes (2002:103-117).

8 Van Niekerk (2002:119-128).

9 Combrinck (2002:137-146) gee 'n oorsig oor die uitdagings.

10 Hierdie vraag kan inderdaad gevra word. Een opname na die ander dui daarop dat wat die kerk leer, en wat die lidmate uitleef, dikwels ver van mekaar verwyder is. Daar is ' $n$ moraliteitskrisis op baie terreine te bespeur. 
Hierdie kom na aan die fokus van die referaat van vandag: die kwaliteit christenskap van ons mense. Reik die kerk helend uit na die mense in die beveiligingsdienste? En die strafproses? En die korrektiewe dienste? Sending beteken om " $n$ verskil te maak in die samelewing. Is die kerk missionêr besig? ${ }^{11}$

Oor die ekologiese terrein sou ek baie wou sê. Is dit nie uiteindelik die finale konteks waar ons getuies vir Christus moet wees nie? "Want so lief het God die wêreld gehad...". Die welsyn van die omgewing, holisties verstaan, is eintlik die terrein waar die kerk ons Vader, die Skepper van die heelal, moet verteenwoordig ${ }^{12}$.

\section{DIE GODSDIENSTIGE TERREIN}

Die twee geestestrominge waarop ons vandag fokus, hou baie nou verband met die twee groot statistiese tendense wat ons in die SuidAfrikaanse kerklike lewe aantref: aan die een kant is daar die duidelike teruggang van die gevestigde ("hoofstroom") kerke; en, aan die ander kant, die ongetwyfelde groei van die nuwer, meer onafhanklike kerke.

\subsection{Die afnemende lidmaattal van die gevestigde kerke}

In ' $n$ noukeurige analise van die bevolkingsensusse sedert 1911 het Jurgens Hendriks en Johannes Erasmus (2002:29) tot die gevolgtrekking gekom dat die tipies Westerse tendens van " $n$ afnemende Christendom vanaf 1980 in Suid-Afrika sigbaar word. Dit is veral te vind in die blanke bevolkingsgroep: die 91,4\% affiliasie in 1980 het teen 1996 op $77,5 \%$ te staan gekom (Hendriks \& Erasmus 2002:28) ${ }^{13}$. Mense het toenemend die kerke begin verlaat. Dieselfde tendens is egter ook sigbaar in die ander bevolkingsgroepe (behalwe die Asiërs), al is dit minder skerp. Miskien is dit minder by die ander omdat die westerse gees hier tog nog minder van 'n houvas opgebou het.

Bo en behalwe hierdie tendens is daar die verskynsel dat die tradisionele hoofstroom-kerke in terme van die aandeel in die bevolking, sowel as hulle aandeel aan die totale christen-groep aan die retireer is. Hierdie eertyds invloedryke groep is nou minder as helfte van die christene. Hierdie afname gekontrasteer met die groei in, enersyds, die charismaties/pinkster groeperings, en, andersyds, die onafhanklike swart

\footnotetext{
11 H Conradie (2002:163-172) kom met 'n hele aantal praktiese wenke.

12 E Conradie (2002:179-198).

13 Die absolute afname is veral onrusbarend: vanaf die 4,1 miljoen blanke christene in 1980 tot 3,4 miljoen in 1996; dit het natuurlik ook baie te doen met die afname van die blanke bevolking.
} 
kerke (van allerlei aard) ${ }^{14}$. Wat besonder interessant is, is dat die RoomsKatolieke Kerk, wat in sy bevolkingsamestelling feitlik die SuidAfrikaanse bevolking weerspieël, steeds matig groei. Waarskynlik is die krimp- en groei-effekte van die strominge deur die bevolkingsamestelling in hierdie Kerk uitgebalanseer.

My mening is dat ten minste een van die redes vir hierdie verdwyn-verskynsel is dat die mens wat deur die globale sekularisasie van die samelewing voortgebring word nie meer veel het aan formele, tradisionele strukture nie ${ }^{15}$. In sy harde vorm het sulke mense materialisties geword; die geestelike, nie-materiële is nie meer belangrik nie. In sy sagte vorm privatiseer hierdie mense hulle godsdiens. Hulle is mense met "n "faith without a need of a church" (Siaki 2002:47).

\subsection{Die groei van onafhanklike kerke}

Terselfdertyd is daar " $n$ dramatiese groei in die geledere van die "nuwer" kerke. Hulle is van twee soorte: die vroeëre onafhanklike swart kerke ${ }^{16}$ (tradisioneel verdeel tussen die Ethiopiese tipe, wat hier nie relevant is nie, want hulle groei is grootliks verby; en die Gees-kerke ${ }^{17}$, wat weer bestaan uit die Sioniste en die Apostoliese groepe), en die Gees-kerke van die charismatiese soort ${ }^{18}$.

Netsoos die afname in die westerse tradisionele christendom lyk na ' $n$ wêreldwye verskynsel, is dit ook met die groei van die onafhanklike kerke. Ek meen dat ons tema van vandag baie hiermee te doen het.

Die opkoms van die pinkster/charismatiese beweging, veral in die afgelope paar dekades, het (meen ek) te doen met die mate waarin die tradisionele kerke ' $\mathrm{n}$ huwelik aangegaan het met die moderne (en postmoderne) tydgees. Twee aspekte hiervan is ter sake. Aan die een kant het

14 Dit blyk dat die ou benaming van hoofstroom (mainstream) kerke nie meer water hou nie. Wie is nou eintlik die hoofstroom? In ' $n$ volgende paragraaf sal ek aan hierdie groeitendense aandag gee.

15 Hendriks (2001:67-72).

16 Die algemene Engelse afkorting AIC dui òf op African Independent Churches, òf African Indigenous Churches, òf African Initiated Churches.

17 Prof Dionne Crafford (1990:17-18) verkies ook hierdie indeling, op voetspoor van Daneel. As die praktyk en lering van sommige van hierdie mense bestudeer word, kom die vraag soms op: is dit die Gees van God wat hier so opgewek word, of dalk ' $n$ ander gees? Soms word hierdie groep dus as G(g)eeskerke beskryf - waarmee hierdie onrus verwoord word.

18 Navorsers soos Allan Anderson het al hierdie groepe (Sioniste en Apostolies) Pinksterkerke gedoop (1991). Sy standpunt word nie deur almal aanvaar nie, maar dit is ' $n$ baie interessante siening, met belangrike raakpunte met my uiteensetting hier onder. 
die kritiese afstand tussen kerk en wêreld vervaag, en het die kerk bewustelik "n teologie aanvaar waarvolgens die kerk "wêrelds" moes wees, positief oor "God se wêreld" moes dink" ${ }^{19}$. Aan die ander kant is veral in die (sekulêre) bestudering van die godsdiens en die Bybel toenemend vrae gevra wat die fondamente geskud het ${ }^{20}$. Onafhanklike charismatiese kerke, en die tradisionele pinkster of evangeliese kerke het hierop gereageer met ' $n$ meer fundamentalistiese siening van die kerk en die verlossing uit die wêreld. Dit het mense getrek wat meer sekerheid gesoek het, en wat ' $n$ basiese onrus oor die nuwe tendens in die teologie gehad het ${ }^{21}$.

Die groei van die swart onafhanklike kerke het weer alles te doen met die aanpassing aan en inkulturasie in die tradisionele Afrika kultuur. Die aanvanklike ontstaan van hierdie kerke het baie te doen gehad met die vreemdheid van die westerse (sending) evangelie ${ }^{22}$. Die hedendaagse pogings tot inkulturasie (bewustelik of onbewustelik) het die voortgaande groei gestimuleer. Hierdie kerke was vir die swart Afrikane "a place to feel at home". Hierdie groei word natuurlik verder gestimuleer deur die jongste beklemtoning van die terugkeer na ou waardes in die Afrika Renaissance. Dit is interessant in watter mate die aanvanklike antipatie teenoor hierdie kerke mettertyd plek gemaak het vir (versigtige) waardering, ook in die geledere van die eertydse sendingkerke ${ }^{23}$. Hierdie

19 Veral in die sestigerjare is sekularisasie positief bejeën. Teologiese strominge soos die Bevrydingsteologie en Politieke Teologie het groot invloed gehad. Die doel van sending was "humanisasie" (vgl Beyerhaus 1969), die terrein van sending was hoofsaaklik die horisontale betrokkenheid by die welsyn van die wêreld.

20 Hier kan veral verwys word na die publisiteit wat die sogenaamde Nuwe Hervorming geniet. Hierdie beweging sluit natuurlik aan by 'n veel ouer kritiese teologie wat vroeër net nie so bekend was in kerklike kringe in Suid-Afrika nie.

21 Natuurlik moet hierdie groei-verskynsel nie net so reaksionêr verstaan word nie. Die werk van die Gees, die regte beklemtoning van die basiese christelike waarhede, en die vertroue op die gesag van die Skrif is alles positiewe elemente. So ook bied die klem op ' $n$ persoonlike verhouding met Christus, en die vrymoedige uitreik na alle mense met die evangelie van verlossing, 'n sterk groeikrag.

22 Hieroor is algemene eenstemmigheid. Sedert 1948, met Bengt Sundkler se eerste boek oor hierdie verskynsel (Bantu Prophets in South Africa) tot die modernste studies word beklemtoon dat die bewustelike of onbewustelike westerse aard van die vroeë kerke, op die lang duur vir baie Afrikane nie bevredig het nie. Hulle wou christene wees op hulle eie manier. Vergelyk byvoorbeeld Daneel (1987).

23 In die sewentigerjare in die Ned Geref Kerk in Afrika is niks positiefs oor hierdie "sektes" gesê nie. Deesdae word op baie vlakke openlik erken dat hulle 'n punt beet het. 
kerke word deesdae eerder gesien as pioniers op die terrein van kontekstualisasie en/of inkulturasie ${ }^{24}$.

\subsection{Naamchristendom van twee soorte}

Die groot saak waaraan ons moet aandag gee, is die oorheersende situasie wat die nominalisme, die naamchristendom, tans in Suid-Afrika inneem.

Evangelisering bly een van die prioriteitsterreine vir die kerk. Watter evangeliseringsuitdaging is daar egter vir die kerk in Suid-Afrika in die lig van die sensusgegewens wat aandui dat drie-kwart van die bevolking christene is? Ek meen dat hierdie primêre taak in ons konteks eerder beskryf moet word as her-evangelisering. Natuurlik is daar altyd "eerste evangelisasie" nodig. Onder andere moet elke nuwe geslag opnuut met die evangelie bereik word, veral wanneer " $n$ situasie van naamchristendom begin heers. Dan is daar ook plekke en groepe mense waar die evangelieverkondiging maar baie skaars was in die verlede ${ }^{25}$. Nogtans dink ek die situasie vra ' $n$ nuwe en andersoortige benadering.

\subsubsection{Die post-christene}

Die eerste soort nominaliteit is egter die "post-christendom", naamlik hulle wat vir alle praktiese doeleindes die kerk verlaat het, al het hulle dit nie offisieel gedoen nie. Siaki (2002:42 e.v.) wys op 'n paar aspekte hiervan. Die eerste is die groeiende getal mense wat in die sensusopname weier/nalaat om die vraag oor godsdiens te beantwoord. Alhoewel nie te veel hiervan gemaak moet word nie, is dit tog ' $\mathrm{n}$ aanduiding van ' $\mathrm{n}$ gebrek aan toewyding ${ }^{26}$. Die tweede saak is die aansienlike verskil tussen die getalle van christene soos aangedui in die bevolkingsensus en die getalle wat op die boeke van die kerke verskyn. Daar is " $n$ goeie derde (tot helfte) van die sensus "christene" wat klaarblyklik nie regtig kerklidmate is nie $^{27}$.

\footnotetext{
24 Vgl Kritzinger (2001:1119-1133).

25 In die navorsingsprojek oor die Onvoltooide Sendingtaak is hierop gekonsentreer. Dit was duidelik dat veral gebiede in die (huidige) Limpopo, KwaZulu/Natal en Oostelike provinsies nog baie swak bereik is met die evangelie.

26 Erasmus het in ' $n$ artikel in die South African Christian Handbook 2001/2002 op hierdie groep mense ingegaan.

27 Hierdie is ' $n$ moeilike terrein vir eksakte syfers. Ekself het in navorsing in Venda in die tagtigerjare ' $n$ diskrepansie van ' $n$ derde gevind (Kritzinger 1982). Siaki (2002:34) vergelyk die Metodiste kerk se eie syfers van ongeveer 1,4 miljoen met die sensussyfer van 2,8 miljoen... 'n helfte. Brierley (1988) bereken die syfer van "ingeskrewe" lede vir Afrika as geheel as 49\%, slegs $28 \%$ van die Anglikane in Afrika is werklik lidmate.
} 
Hierop moet ons nog ' $n$ bietjie dieper ingaan. Die $75 \%$ sensuschristene in Suid-Afrika, beteken dus nader aan 50\% tot $60 \%$ kerklidmate. Nou is dit so dat net ' $n$ kleinerige persentasie hiervan - die Ned Geref Kerk se opnames dui op ongeveer ' $n$ derde van die Ned Geref Kerk lidmate - op ' $n$ redelik gereelde basis die eredienste bywoon. Ek weet nie of mens die Ned Geref Kerk se erediensbywoning as verteenwoordigend vir al die kerke kan beskou nie. Ek is eerder geneig om te dink dat dit dalk hoër is as die meeste ander kerke. Maar as ons kerkbywoning as ' $\mathrm{n}$ aanduiding van meelewendheid en toewyding beskou, is dit met ander woorde so min as $20 \%$ van die Suid-Afrikaanse bevolking wat as enigsins meelewende christene beskou kan word ${ }^{28}$. [Hierdie soort berekeninge is relevant wanneer ons nadink oor die impak van die evangelie in die gemeenskap.

Onder andere toon hierdie argument aan hoedat die statiese onderskeid tussen sending/evangelisasie en kerkopbou net nie opgaan nie. Een van die belangrikste (sending)uitdagings vandag is in die kerk, in die bereiking, die bekering, die re-evangelisering van die miljoene naamchristene in ons land.

\subsubsection{Die sinkretistiese christene}

Naamchristene is nie net die christene wat afgeskakel het nie, maar ook daardie miljoene meelewende christene wie se christenskap sodanig gekleur is deur ' $\mathrm{n}$ sinkretisme ${ }^{29}$ dat hulle gevaar loop om as christene in naam beskou te word. Wie is hulle? Ek sien hier drie groepe.

- Die eerste is die westerse christene wie se christelike styl identies is aan die kapitalistiese, globalistiese, Amerikaanse kultuur. Hulle christenskap pas net te mooi in in die heersende kultuur. Hierdie is wat al die "civil religion" (burgerlike godsdiens) genoem is. Hierdie uitdaging is uit die aard van die saak nie altyd so hoog op die agenda van gemeentes met wie dit skynbaar goed gaan nie. Hierdie gemeentes loop die gevaar om net "n "diens" aan hulle lidmate

28 Kan ek nog ' $n$ stap verder gaan? Watter persentasie van hierdie $20 \%$ is christene in die evangeliese sin van die woord: mense wat hulleself bewustelik aan Christua oorgegee het, en daagliks bewustelik as christene probeer leef? Hier beweeg mens op dun ys. Die gesaghebbende Operation World (Johnstone \& Mandryk 2001:577) stel die getal "Evangelicals" in Suid-Afrika op 19,3\%. Die verduideliking van hulle definisie en berekening kan nagelees word op bladsye 756-757.

29 Ek is maar te bewus daarvan dat die term sinkretisme op baie verskillende maniere gebruik kan word. Mens kan en moet selfs ook praat van positiewe sinkretisme, naamlik die mate waarin die evangelie tuisgekom het in ' $n$ betrokke kultuur en konteks, sonder dat die essensie van die evangelie prysgegee is. Sinkretisme is dan ' $n$ uitdaging. Hier gebruik ek dit op die (gewone) negatiewe manier: die kultuur het essensieel die evangelie oorwin. 
te bied. Die predikant en die organisasie is die lede ter wille, daarvoor word hulle betaal. Die lede se gewete word net aangespreek in die mate wat dit die behoefte daaraan beantwoord ${ }^{30}$. Aan die ander kant is daar die gevaar by groeiende gemeentes dat hulle so sogenaamd "seeker sensitive" is dat eintlik " $n$ knieval voor die huidige kultuur gemaak word ${ }^{31}$.

- Die tweede groep naamchristene is hulle wat iewers in die verlede kerklidmate geword het, maar wat vir alle praktiese doeleindes weer heidene geword het, "die teenswoordige wêreld liefgekry het", in die woorde van Paulus in 2 Timoteus 4:10. Hulle het geen betrokkenheid meer by die kerk nie. Die redes hiervoor kan wees dat hulle hulself onttrek het. Maar in baie gevalle is dit die gevolg van ' $n$ ontoereikende bediening deur die kerk. ' $n$ Voorbeeld wat vir my baie na aan die hart lê, is die miljoene (swart) plaaswerkers in die uitgestrekte landbougebiede van ons land. Jare gelede is hulle bearbei en het kerklidmate geword, maar weens ' $n$ verskeidenheid van omstandighede word hulle vir jare reeds nie meer bedien nie. Hulle het grootliks teruggesink in ' $n$ tradisionele lewenswyse, maar met " $\mathrm{n}$ christelike sousie oor. Die sterk onderliggende basis van die nie-christelike het maar weer hulle lewe begin oorheers ${ }^{32}$.

- Die derde groep wat ek sien is die miljoene lede van daardie onafhanklike swart kerke wat eintlik ' $n$ swak christelike fondament het ${ }^{33}$. Hulle noem hulleself christene, en kerke, maar die bron

30 Wyle Lesslie Newbigin het, na ' $n$ leeftyd van sendingwerk in Indië, by sy terugkeer in die Verenigde Koninkryk die westerse christendom attent gemaak daarop dat die kerk in die weste die taak skromelik verwaarloos het om hulle eie kultuur te kersten. Die westerse samelewing en kultuur was nog nooit, en is nie "christelik" nie. Hy het " $n$ beweging wakker gemaak wat in die VSA genoem word "The Gospel and Our Culture Network" (GOCN). Dit is gaaf dat daar ook in Suid-Afrika "n aktiewe werkgroep in hierdie verband is. Kontak jniederh@mweb.co.za.

31 Terwyl die missionêre ingesteldheid van gemeentes toegejuig moet word, moet tog geleer word uit die foute van die eeuelange sendinggeskiedenis. Meestal is die kultuur op " $n$ onnodig negatiewe wyse van die hand gewys, met negatiewe gevolge vir die tuiskoms van die evangelie, maar daar is ook gevalle waar onwyse kompromieë met die kultuur aangegaan is.

32 Hierdie voorbeeld is baie relevant, want dit is inderdaad ' $n$ uitdaging aan die deur van die kerk. ' $n$ Groot persentasie van kommersiële boere is belydende christene, maar hierdie situasie het onder hulle neuse ontwikkel. Is dit dalk nog ' $n$ aanduiding hoedat die kultuur (van verhoudinge) ' $n$ negatiewe invloed op die voortgang van die evangelie gehad het?

33 Ek probeer doelbewus om nie te veralgemeen nie. Hierdie groep kerke, wat in benaming onder dieselfde noemer gebring word, verskil grootliks onderling. Daar is baie van hulle wat selfs fundamentalisties bybelgelowig is. Ongelukkig is daar egter 
van die christelike lewe - die Bybel - geniet òf nie die nodige aandag nie, òf word so verdraaid hanteer, dat die unieke christelike elemente van die geloof grootliks afwesig is. En hierdie groepe behoort tot die snel groeiende sektore van die Suid-Afrikaanse samelewing. Die faktor in hulle groei is egter hulle onkritiese teruggrype na die tradisionele. Hier het die sentiment van die Afrika kultuur die oorwinning behaal, al is daar ook ' $n$ simpatie met die godsdiens van die moderne wêreld waarvan hulle deel geword het.

\section{SLOT}

Die uitdagings - oud en nuut - in die Suid-Afrikaanse samelewing loop wyd en diep. Die kerk moet dit alles in die oë kyk. Ongelukkig is een van die kenmerke van die hedendaagse samelewing dat alles baie vinnig moet geskied. Daar moet kitsoplossings vir alles wees. Die feite herinner ons egter daaraan dat daar nie "quick fixes" gesoek moet word nie. Wat gevra word, is " $n$ grondige oorgawe aan die taak waartoe die Here sy kerk geroep het.

\section{Literatuurverwysings}

Anderson, A 1991. Moya. The Holy Spirit in an African Context. Pretoria: Unisa.

Beukes, P 2002. Life before death - socio-economic justice issues and mission: the economy, poverty and the church, in: Kritzinger (ed), 103-118.

Beyerhaus, P 1969. Humanisierung. Einzige Hoffnung der Welt? Bad Salzuflen: MBKVerlag.

Brierley, P 1998. Future Church: a Global Analysis of the Christian Community to the Year 2010. East Sussex: Monarch Books.

Brink, V 2002. The Educational Scene, in: Kritzinger (ed), 147-161.

Combrinck, J 2002. HIV?AIDS: the Impact and Challenge of the Pandemic, in: Kritzinger (ed), 137-146.

Conradie, E 2002. Earthkeeping: a Challenge to the Church in South Africa, in: Kritzinger (ed), 179-198.

Conradie, H 2002. Violent Crime in South Africa, in: Kritzinger (ed), 163-172.

Crafford, D 1990. Uitdagings vir die Kerk in Afrika. Pretoria: NGKB.

Daneel, M L 1987. Quest for Belonging. Introduction of a study of African Independent Churches. Gweru: Mambo Press.

Erasmus, J 2001. Who are the people of "no religion"?, in: Odendal (ed), 83-91.

Hendriks, J 2001. Religion in South Africa. Census 1996, in: Odendal (ed), 29-81.

ook daardie - en sommige van hulle is groot en invloedryk - wat nie anders as sinkretisties (in die negatiewe sin van die woord) beskou kan word nie. 
Hendriks, J and Erasmus, J 2002. A General Statistical Picture of Religion in South Africa, in: Kritzinger (ed), 13-30.

Johnstone, P and Mandryk, J 2001. Operation World. Carlisle: Paternoster Lifestyle.

Kekana, N F 2002. Religion and Human Rights: with particular reference to freedom of religion, internecine Christian tensions, in the context of a secular state, in: Kritzinger (ed), 81-89.

Kritzinger, J J 1982. Die Onvoltooide Sendingtaak in Suid-Afrika. Deel 8: Venda. Pretoria: ISWEN.

-, 1988. Die Onvoltooide Sendingtaak in Suid-Afrika. Pretoria: ISWEN.

-, 2001. Welkom by die brug: Opmerkings oor die brugfunksie van die Afrika Onafhanklike Kerke. HTS 57(3\&4), 1119-1133.

-, (ed) 2002. No Quick Fixes. The Challenge of Mission in a Changing South Africa. Pretoria: IMER.

Lubbe, G 2002. Religio-Political Changes in South Africa, in: Kritzinger (ed), 61-69.

Odendal, H (ed) 2001. South African Christian Handbook 2001/2002. Tyger Valley: Christian Network Media and Tm.

Siaki, P 2002. Christianity in the New South Africa: another look at the Statistics, in: Kritzinger (ed), 31-60.

Sundkler, B 1948. Bantu Prophets in South Africa. London: Lutterworth.

Van Niekerk, A S 2002. A Strategy against Poverty in South Africa, in: Kritzinger (ed), 119-128. 